THE IMPLEMENTATION OF

OBLIGATORY UIRTUALITY IN

THE UNIUERSITY ENUIRONMENT

IN AN EXTRAORDINARY CONTEXT.

FROM THE THEORY

\title{
TO THE PRACTICE
}

\section{KEYWORDS}

Higher education; ICT; classroom-workshop.

\section{ABSTRACT}

This article will present pedagogical proposals made by the authors for the Architecture I chair. These ideas arise from the attempt to apply the theoretical background provided by the University Degree in ICT-Mediated Education of the UNNE in an exceptional context of pandemic, where virtuality is presented as the only possible didactic alternative. Likewise, conclusions will be drawn about its application. 


\title{
LA IMPLEMENTACIÓN DE LA UIRTUALIDAD OBLIGATORIA EN EL ÁMBITO UNIUERSITARIO EN UN CONTEXTO EXTRAORDINARIO. DE LA TEORIIA A LA PRÁCTICA
}

\author{
CURRIE, Laura G.; GOVER, Olivia \\ currie.laura.gisela@gmail.com
}

- Jefa de Trabajos Prácticos por concurso en la cátedra Arquitectura I - UP "A" (FAU-UNNE). Becaria de Investigación de Perfeccionamiento. Secretaría General de Ciencia y Técnica (SGCyT-UNNE). - Auxiliar de primera categoría por concurso en la cátedra Arquitectura I UP "A" (FAU-UNNE). Adscripta por concurso en la cátedra Museología de la carrera Licenciatura en Gestión y Desarrollo Cultural (FADyCC-UNNE).

PALABRAS CLAUE

Educación superior; TIC; aula-taller.

RESUMEN

En el siguiente artículo se expondrán propuestas pedagógicas realizadas por las autoras para la cátedra Arquitectura I. Dichas ideas surgen de la tentativa de aplicar el bagaje teórico suministrado por la Diplomatura Universitaria en Educación Mediada por TIC de la UNNE en un contexto excepcional de pandemia, donde la virtualidad se presenta como la única alternativa didáctica posible. Asimismo, se extraerán conclusiones sobre su aplicación. 


\section{OBJETIUOS}

\begin{abstract}
- Adecuar la modalidad aula-taller de una materia de concepción práctica, anual, presencial, de primer año de la carrera de Arquitectura a una modalidad estrictamente virtual.

- Establecer estrategias que puedan ser utilizadas en espacios universitarios con similares características. - Aplicar los contenidos teóricos aprendidos sobre educación en línea desarrollados en la Diplomatura Universitaria en Educación Mediada por TIC en un ámbito académico real.
\end{abstract}

\section{PLANTEO DEL PROBLEMA}

Al aislamiento social preventivo obligatorio decretado como medida gubernamental contra el avance de la pandemia originada por la COVID-19, que provocó el cierre de universidades y la activación inmediata de un régimen educativo estrictamente virtual, se suma, en la Facultad de Arquitectura y Urbanismo de la Universidad Nacional del Nordeste, la reciente implementación de un nuevo Plan de Estudios y, en el caso concreto que vamos a exponer, la complejidad adicional de ser una asignatura de primer año de la carrera. Para comprender las implicancias de estos factores y cómo se entretejen para generar el complejo escenario actual, resulta necesario su desarrollo. La implementación de la cuarentena se produjo un 17 de marzo, que debía ser el primer día de clases de la asignatura Arquitectura I del primer año de la carrera de Arquitectura, por lo cual no se pudo concretar ningún encuentro presencial con un grupo de estudiantes cuya única y breve experiencia universitaria fueron las actividades académicas para ingresantes, desarrolladas en el "Espacio A" desde el 10 al 28 de febrero de 2020. Asimismo, en el ciclo lectivo anterior, se implementó un nuevo plan de estudios, lo cual desestimó las planificaciones previas de cátedra para ir concibiendo otras experiencias didácticas, en conjunto con las restantes asignaturas del primer año de la carrera. Es decir, a la carencia de poder contar con una planificación anual debido a la interdependencia de asignaturas se sumó la implementación de la modalidad a distancia en una materia de concepción práctica, que solo contaba con incipientes esbozos en el campo de la virtualidad, entendida como complemento a la presencialidad, no como única forma posible. Cabe volver a destacar que se trata de estudiantes que han ingresado por primera vez a un ámbito universitario, y que, además, lo han hecho en un escenario pre-pandemia, apostando a una educación presencial, donde la virtualidad no formaba parte del contrato académico. Por lo expuesto, este artículo pretende contrastar los aprendizajes adquiridos durante la Diplomatura Universitaria en Educación Mediada por TIC (en adelante DUEMT) con las experiencias de aplicación de estos ante este nuevo escenario educativo.

\section{DESARROLLO}

\section{Marco de referencia}

La propuesta se circunscribe en el ámbito de una materia anual, práctica, de primer año de la carrera de Arquitectura, enmarcada en el área del Diseño y la Producción. En ella se abordan conocimientos proyectuales poniendo al estudiante en situación de diseñar soluciones ante un tema-problema. Se trabaja de lo general a lo particular, con un bloque de contenidos a lo largo del año. A medida que avanza el ciclo lectivo, aumenta la complejidad de lo que se desarrolla. Debido a que se puede elegir entre tres propuestas pedagógicas para cursar la asignatura obligatoria de la currícula, cada año el número de inscriptos varía. Sin embargo, podemos señalar que por año, en promedio, se cuenta con 200 alumnos.

\section{Organización}

La organización del artículo estará regida por los contenidos desarrollados en la DUEMT, respetando el orden cronológico, mientras se expone su posible aplicación en una realidad académica concreta.

\section{Gestión de aulas virtuales en Moodle} Ante la situación previamente explicitada, como primera medida fue necesario establecer un canal de comunicación virtual de la cátedra con los estudiantes. En este caso, no se aplicó el Aula Moodle, sino que se propuso utilizar como herramienta una red social: Facebook. Las razones fueron la familiaridad de la asignatura con esta red, la cual se utilizó en años anteriores como complemento a la presencialidad, y la necesidad de buscar soluciones rápidas ante una situación impostergable que exigía una veloz adecuación tanto del equipo docente como de los estudiantes.

La página de Facebook, creada en años anteriores, era utilizada solo para subir información, por lo que no se encontraba habilitada la función para comentarios y, por ende, carecía de interacción con los estudiantes. Bajo el escenario descripto se propone convertir la página de Facebook en un Grupo Cerrado, conformado solo por los estudiantes del ciclo lectivo en curso y el equipo docente, creando un ámbito privado que favorezca el intercambio. Asimismo, se escoge el grupo de tipo aprendizaje social, el cual brinda las siguientes ventajas: - los administradores pueden organizar publicaciones en unidades y cambiar el orden en el que aparecen. 
- Ios miembros del grupo pueden hacer clic en "listo" para informar al administrador que interactuaron con la unidad.

- los administradores pueden ver las estadísticas del grupo, además de detalles sobre la finalización de unidades y publicaciones (Facebook, 2020).

En el grupo cerrado de Facebook se propone habilitar los comentarios y la opción de generar una reacción a las publicaciones realizadas a través del "me gusta", convirtiéndolo en el canal institucional de intercambio de la cátedra. Para su administración se recomienda docentes con manejo de las redes, tecnología y antecedentes de cursos en docencia virtual. Serán los encargados de subir la información y, al inicio del cursado, del intercambio con los estudiantes a través del grupo creado.

Se plantea para el día pautado de inicio de actividades una breve presentación escrita dándoles la bienvenida, comentando la finalidad del espacio creado y sus normas de utilización. Además se propone un video de presentación de la cátedra vinculado desde YouTube, para que los estudiantes puedan conocer a los docentes e identificarlos.

\section{El rol tutorial en la enseñanza mediada por TIC}

Dentro de esta experiencia de aplicación del grupo cerrado de Facebook como canal de comunicación y de construcción de conocimiento con los estudiantes, se propone ejercer el rol de docente tutor, entendiéndolo como

Consejero, asesor o animador, comoaquel docentequepromueve el aprendizaje para lograr ciertas competencias en los alumnos. Su competencia profesional se centra en la delicada función de orientar y mediar entre los aprendizajes de los alumnos adultos y los contenidos a enseñar, los materiales propuestos y las comunicaciones emitidas por el sistema EV: estimular la motivacióny mantener la atención orientada a los núcleos conceptuales de los temas a estudiar (Grau, s/f., p. 16).

Asimismo, la Educación Virtual supone un cambio en el rol del docente, el cual debe, además de atender a cuestiones del proceso de enseñanza-aprendizaje, solucionar aspectos tecnológicos de la plataforma escogida. Se propone implementar en cada documento palabras de estímulo y aliento a los estudiantes, además de asignar docentes del equipo con formación en educación virtual para manejar el grupo de Facebook y responder consultas de los alumnos de carácter conceptual, procedimental y tecnológico.

\section{Diseño de materiales didácticos para la educación superior mediada por TIC}

Al no contar con la posibilidad de trabajar los contenidos teóricos en las correcciones grupales bajo el formato de colgadas o enchinchadas, la necesidad de elaborar materiales didácticos para el desarrollo de cada trabajo práctico cobró mayor importancia. Como afirma Gisela Schwartzman (2013):

En el marco de la Educación en Línea, la tarea de enseñar se pone en juego, principalmente, a través de tres acciones complementarias: el diseño de materiales didácticos, las tareas de aprendizaje que se proponen a los estudiantes para su realización y las interacciones reales que el docente lleva adelante con los mismos a través de diversos espacios y medios (Párr. 38)
Entendemos por material didáctico a Aquellos con los que el estudiante interactúa en forma directa como parte de su proceso de construcción de conocimientos y que son concebidos, desde el mismo proceso de diseño, para sostener, apoyar, guiar orientar procesos de aprendizaje (...) Los materiales didácticos cobran sentido sólo en el marco de la propuesta de enseñanza que los contiene. Es decir, los materiales no son elementos cerrados en sí mismos, sino que son parte de una propuesta educativa que los incluye, pero que no se limita a estos (Schwartzman, 2013, Párr. 8)

Se propone la elaboración de materiales que aborden temáticas particulares, a partir de la detección de necesidades que subsanar en las correcciones de los trabajos prácticos y como guía e insumo para el desarrollo de estos. Asimismo, en pos de brindar una multiplicidad de voces y formatos, se recomienda como bibliografía la inclusión de material audiovisual seleccionado, presente en Internet, que se constituye en "otros recursos y materiales de la cultura que, creados con otros propósitos, vuelven a cobrar nuevos sentidos al ser utilizados por un docente que los incluye en sus propuestas de enseñanza" (Schwartzman, 2013, Párr. 8.). Es decir que, si bien dichos materiales no fueron creados con este fin educativo en particular, complementan la intencionalidad pedagógica de la cátedra brindando la posibilidad de orientar el pensamiento y construir conocimiento por parte de los estudiantes a partir de la heterogeneidad y pluralidad de relatos.

Al igual que los materiales didácticos, la inclusión de presentaciones visuales también cobra una nueva 
importancia en el escenario virtual. Como expone Solano Fernández (2007), "las presentaciones visuales son modos de facilitar información combinando imágenes y textos en un único soporte" (p. 1).

Se plantea realizar presentaciones visuales como complemento de la consigna brindada para el desarrollo de los trabajos prácticos. Dichas presentaciones servirán como hoja de ruta para los estudiantes. Además, en ciertos casos, se aconseja incluir una voz en off que las acompañe, lo que da como resultado un material audiovisual.

\section{Prácticas e instrumentos de evaluación}

Para aspirar a una evaluación transparente, se propone explicitar en el enunciado de la consigna de cada trabajo práctico qué aspectos se evaluarán, además de la clarificación de los objetivos que persigue la actividad. Como indica Ahumada Torres (2012)

Evaluar de forma objetiva, fiable y transparente no resulta fácil siendo un elemento crítico el método de evaluación que se aplicará; este debe estar directamente relacionado con lo que se pretende evaluar, con las actividades que se han realizado (contenido y metodología) y con aquello que se le ha comunicado al estudiante que se le demandará (p. 26).

Considerando que se trata de una materia anual, en la cual prima el proceso del estudiante, se propone realizar fichas de seguimiento, que contengan información personal de ellos (requerida mediante formulario de Google que los estudiantes completan adjuntando una fotografía), donde se vuelque su desarrollo académico. Asimismo, para evaluar el desarrollo de cada actividad práctica, se propone el armado de rúbricas. Esta herramienta permite "revelar los niveles de consolidación alcanzados ante un objetivo, una competencia o grupo de competencias por parte del alumnado" (Ahumada Torres, 2012, p. 26)

Como aseguran Gatica et al. (2013) "las rúbricas o matrices de valoración brindan otro horizonte con relación a las calificaciones tradicionales que valoran el grado de aprendizaje del estudiante, expresadas en números o letras" (p. 61). En el ámbito del diseño resultan particularmente útiles, ya que "como instrumentos de evaluación formativa facilitan la valoración en áreas consideradas subjetivas, complejas o imprecisas mediante criterios que cualifican progresivamente el logro de aprendizajes, conocimientos y/o competencias" (Gatica et al., 2013, p. 62). Son "tablas que desglosan los niveles de desempeño de los estudiantes en un aspecto determinado, con criterios específicos sobre rendimiento. Indican el logro de los objetivos curriculares y las expectativas de los docentes" (Gatica et al. 2013, p. 61). Dentro de sus ventajas, las autoras reconocen las siguientes:

- Se identifican claramente objetivos docentes, metas y pasos que seguir. - Señalan los criterios que medir para documentar el desempeño del estudiante.

- Cuantifican los niveles de logro que alcanzar

- Se brinda retroalimentación luego de identificar áreas de oportunidad y fortalezas.

- Disminuyen la subjetividad de la evaluación.

- Permiten autoevaluación y co-evaluación (Gatica et al., 2013, p. 64).

En cuanto a la retroalimentación, se propone que las rúbricas sean utilizadas como insumo para reconocer, dentro de cada comisión, los aspectos que tuvieron un grado menor de desempeño, para ser trabajados con los estudiantes, considerando la evaluación como un engranaje más en el proceso de construcción de conocimiento. Se recomienda fervientemente realizar devoluciones a los estudiantes luego de la evaluación, las cuales, en las actividades introductorias, adoptan el formato de documentos generales para todos los estudiantes, y luego se realizan de manera individual respondiendo al proceso de cada estudiante en particular. Asimismo, otra ventaja que se intenta aprovechar es la disminución de la subjetividad, procurando consenso entre todos los docentes mediante el proceso de evaluación con rúbricas.

\section{Herramientas de colaboración}

En la presencialidad se trabaja con la modalidad pedagógica aula-taller, donde "el aprendizaje se inserta en un proceso pedagógico que es abarcativo y colaborativo entre alumnos y docentes, aprendiendo activamente con base en la experimentación" (Krause, 2018, p. 134). La interacción entre docente y estudiante, y entre estudiantes, se vuelve de vital importancia para construir los conocimientos en forma colectiva, lo cual se daba a través de puestas en común y correcciones grupales, también llamadas colgadas, término que hace referencia a la presentación de avances y entregas de los trabajos en láminas físicas que eran pegadas con cintas en la pared.

Para mantener esta modalidad pedagógica a través del trabajo colaborativo, entendiendo este como "un proceso de interacción en el que los miembros del grupo se asumen responsables de sus acciones e integran las habilidades y contribuciones de sus pares en un esfuerzo 
coordinado para la resolución de un determinado problema" (Andreoli, 2013, p. 3), fue necesario pensar distintas alternativas para generar espacios que permitieran un intercambio entre todos los actores y la comunicación sincrónica con el estudiante, y de este con sus pares. Para generar estos espacios, Andreoli (2013) explica que

Es necesaria una interrelación entre los miembros del grupo, las actividades en las que se comprometen, las interacciones que se desarrollan, las actividades metacognitivas que se disparan de esa interacción (explicación, justificación, acuerdos, desacuerdos, regulación mutua) y los mecanismos cognitivos que estimulan (p. 3).

Teniendo en cuenta esta situación, se propone la utilización de distintas herramientas de colaboración a medida que avanza el cursado, iniciando con la herramienta de presentación Padlet, que permite a los estudiantes exponer sus trabajos en un espacio común, donde pueden visualizar la producción del resto de sus compañeros, como en una colgada presencial.

A medida que se avanza en el cursado se hace evidente la necesidad de generar espacios de intercambio en grupos más reducidos, sobre todo en las etapas de diseño puntualmente. Para ello entre las distintas alternativas propuestas, se seleccionaron dos: 1. La implementación de la comunicación sincrónica a través del uso de la herramienta chat, que permite crear un espacio de intercambio e interacción, atendiendo consultas, dudas y devoluciones a través de mensajes escritos, audios, imágenes de ejemplos, envío de enlaces sobre cuestiones puntuales que permiten acceder a un material didáctico, envío de documentos escritos, tanto entre el docente y los estudiantes, como entre estudiantes, lo que genera un ámbito colaborativo.

2. La implementación de videoconferencias con el fin de generar un espacio de comunicación sincrónica para atender dudas, propiciar debates e intercambio de opiniones. También permite realizar presentaciones para tratar un tema en particular y realizar correcciones de trabajos buscando la participación activa de los estudiantes en la construcción del conocimiento.

Si bien se debe aclarar que no hubo instancias de trabajos grupales como en años anteriores, en palabras de Andreoli (2013), el aprendizaje colaborativo mediado por computadora se focalizó en "analizar cómo la tecnología puede facilitar la interacción de los miembros de un grupo y de qué manera participan en procesos de construcción de conocimiento compartiendo información y recursos" (p. 10).

\section{Uso educativo de las redes sociales en el ámbito universitario}

En el marco de la Educación a Distancia, el medio que se establece para comunicarse pasa a ser el eje organizativo de la propuesta pedagógica. Las tecnologías de la Web 2.0 son el recurso con el que contamos para generar dicho canal de comunicación.

Por su parte, las redes sociales tienden a asumir un protagonismo sustancial en la vida de las personas, intensificado por la situación mundial que estamos atravesando. Como lo explica Argüelles (2013), "las redes sociales se han incorporado de manera importante a la vida de los seres humanos, de modo que se encuentran presentes prácticamente en todos los ámbitos" (p. 3). Por lo tanto, afirma que "es conveniente considerarlas como espacios factibles para hacer llegar información educativa a los estudiantes que, una vez conectados, pueden aprovechar su tiempo para consultar contenidos educativos e interactuar con profesores y otros alumnos" (p. 2).

Teniendo en cuenta este marco es que se propuso utilizar la red social Facebook inicialmente como canal de comunicación para los estudiantes que desearan cursar la materia, y se formó una comunidad de aproximadamente 200 alumnos. Esta propuesta planteó la interacción de la cátedra con los estudiantes a través de publicaciones realizadas en los días establecidos según el cronograma institucional. En ella, los estudiantes podrían plantear consultas y dudas a través de los comentarios, las cuales podrían ser atendidas mediante respuestas al comentario realizado.

Para instancias posteriores, y con la complejización de las actividades que desarrollar, se propone armar grupos para acompañar y guiar en el proceso a cada estudiante. Continuando con la metodología propia de la asignatura, se conformaron comisiones, que exigían un espacio de trabajo conocido y manejable para todos los docentes y estudiantes, que insumiera el mínimo equipamiento tecnológico y requerimiento de redes o datos. Por ello, se propuso utilizar aplicaciones dentro de las Ilamadas Mobile Learning o Aprendizaje Móvil, que, como lo explica Padrón (2013), "son una forma de e-Learning basada fundamentalmente en el aprovechamiento de las tecnologías móviles como base del proceso de aprendizaje" (p. 124).

Los teléfonos móviles dejaron hace tiempo de ser meros mediadores comunicativos para convertirse en centros deinformación, comunicación, registro y edición de audio y video, 
depósito de recursos y contenidos, entre otros. Principalmente, en el proceso de enseñanza y aprendizaje presentan más potencialidades de las que podemos imaginar y están más al alcance de nuestra mano de lo que cabría pensar (Padrón, 2013, p. 124).

Dentro de las aplicaciones llamadas Mobile Learning, se propone utilizar la herramienta de mensajería (XMPP) instantánea, gratuita y en formato multiplataforma: WhatsApp, que como lo menciona Padron (2013), "en el ámbito de la universidad, esta aplicación podría ser utilizada como una herramienta para promover el aprendizaje colaborativo, así como un medio de comunicación potente, asíncrono y constante" ( $p$. 128). Entre las posibilidades que ofrece la aplicación para el aprendizaje colaborativo, nos enfocamos principalmente en que permitiría llevar a cabo debates e impulsar la reflexión, el pensamiento crítico y la argumentación de los estudiantes respecto de sus trabajos y de los pares, motivando la puesta en común, a través de mensajes, audios, videos disparadores, capturas de pantalla, imágenes, entre otros, en grupos de veinte a treinta estudiantes. Además abre un abanico de posibilidades para la evaluación y el seguimiento por parte del docente facilitando una retroalimentación con los estudiantes.

\section{CONCLUSIONES}

Como conclusiones podemos destacar que la implementación de la Educación Virtual fue abrupta por el contexto que así lo exigía y no pudo ir acompañada de la planificación que amerita. Asimismo, cuenta con la desventaja fundamental de depender de una conectividad a Internet y de dispositivos electrónicos que funcionen de vínculo, ya sea teléfono móvil u ordenador, exigencia que no formó parte del contrato pedagógico que asumieron los estudiantes al inscribirse en la carrera. Por dicho motivo, la flexibilización de plazos y estrategias fue clave en el desempeño del primer cuatrimestre del ciclo lectivo, tratando de contemplar situaciones particulares de los estudiantes.

Del mismo modo, la adecuación al sistema virtual implicó el insumo de una gran cantidad de horas por parte de los docentes, que debieron re-diseñar todas las presentaciones, materiales didácticos, herramientas de evaluación, planillas de seguimiento, además del diseño de los trabajos prácticos en conjunto con otras asignaturas. Dichos documentos demandaron también su sistematización, digitalización y guardado en la nube, y generaron un nuevo ámbito colaborativo entre los docentes a través del uso de Google Drive.

En cuanto a la utilización del grupo cerrado de Facebook, la ventaja que se reconoce fue la noción del manejo de la herramienta por parte de los estudiantes y la rápida adecuación de los docentes, lo cual permitió que no se produjeran inconvenientes en el canal creado. Como desventaja podría nombrarse que al no ser una plataforma educativa, tuvo ciertas limitaciones que hubo que saldar a través de la incorporación de otras herramientas de comunicación sincrónica (Zoom, WhatsApp) y de presentación de trabajos (Padlet).

Respecto de la designación de docentes-tutores que oficien de guías durante los primeros momentos de implementación del modelo virtual, se obtuvieron resultados positivos, condensando las consultas de los estudiantes y el manejo de Facebook en dos docentes. De igual forma, luego hubo que descentralizar dicha responsabilidad, la cual fue asumida por todos los docentes en sus subcomisiones materializadas a través de los grupos de WhatsApp.

Si bien la elaboración de materiales didácticos insumió una mayor cantidad de tiempo, consideramos que superó ampliamente la mera recopilación de bibliografía, y, asimismo, permitió la incorporación de materiales educativos en otros formatos, como el video, los cuales no se explotaban en la presencialidad. De la misma manera, la producción de presentaciones visuales también demandó tiempo, porque reemplazaron las antiguas explicaciones verbales del equipo docente, pero fueron una herramienta sumamente necesaria en esta instancia. La pertinencia de dichos materiales fue revisada y puesta en duda mediante la respuesta de los estudiantes en la elaboración de las actividades prácticas y mediante sus consultas, que originaron, a su vez, la profundización sobre ciertas temáticas por parte del equipo docente. Es decir que, si bien son insumos que posee la cátedra para años posteriores, deben ser revisados a la luz del nuevo alumnado y las nuevas intencionalidades didácticas. Las prácticas para la evaluación y los instrumentos propuestos no eran desconocidos para el cuerpo docente, y su aplicación presentaba similitudes con las formas de trabajo utilizadas en la presencialidad. Consideramos que el desafío fue la búsqueda de opciones para que la evaluación formara parte del proceso del estudiante. Esta situación en la presencialidad se trabajaba de manera oral con el grupo de estudiantes.

La puesta en común de las evaluaciones fue tomando distintos formatos a medida que se complejizaban las actividades y los estudiantes comprendían el proceso y empezaban a formar parte de él. Inicialmente la propuesta adoptó una forma escrita a través de la redacción de un docu- 
mento, al cual luego se le agregaron imágenes obtenidas de las propias producciones de los estudiantes para ejemplificar algunos aspectos. Sin embargo, consideramos que esta propuesta no fue acorde con las características de los estudiantes de primer año, en un contexto desconocido, donde aún no manejan conceptos técnicos ni cuentan con experiencia en la ejercitación de la autocrítica, necesaria para poder volcar las devoluciones generales a su producción particular.

Como parte del proceso, al poder generar grupos reducidos en subcomisiones, las maneras de transmitir las devoluciones de los trabajos evaluados tomaron distintas formas. Audios, escritos, comentarios en los documentos en formato PDF entregados por los estudiantes, reuniones por videollamada posibilitaron la creación de un espacio propicio para la retroalimentación pretendida.

Las herramientas colaborativas, por su parte, tuvieron un rol central para lograr un espacio de intercambio, similar a lo realizado en la presencialidad. Una de ellas, Padlet, posibilitó la presentación de avances y trabajos finales, en un mismo espacio y accesible a todos, y permitió iniciar a los estudiantes en la idea de puesta en común para la construcción del conocimiento

El hecho de realizar entregas virtuales posibilitó, además, la exploración de herramientas digitales por parte de los estudiantes, lo que arrojó resultados sumamente interesantes y enriquecedores. Los motivó a mostrar sus propuestas proyectuales de manera creativa, explorando la tridimensionalidad. Sin embargo, es preciso señalar que el uso de la herramienta Padlet, en nuestro caso, nos presentó condicionantes para la propuesta pedagógica, ya que su uso gratuito limita la cantidad de tableros que pueden crearse $y$, por ende, condiciona las instancias de presentación, si se aspira a que estos permanezcan accesibles durante todo el cursado como fuente de información. También se debe tener en cuenta el volumen de trabajos al cual se va a someter al muro, por lo que se hace imprescindible conocer las alternativas de organización que ofrecen esta u otras herramientas, ya que, por ejemplo, al inicio del cursado la lectura de alrededor de 200 posteos, sin una organización aparente, fue compleja.

Dentro de las herramientas colaborativas propuestas, las videollamadas, a través de la aplicación Zoom, tuvieron lugar durante el último mes del cuatrimestre. Esta fue una herramienta muy útil para evacuar dudas y consultas y posibilitó las correcciones grupales. Se seleccionaban trabajos de los estudiantes para mostrarlos en las reuniones virtuales, brindando la posibilidad al estudiante que lo deseara de explicar su propuesta, y al resto de sus compañeros que ingresaran en la reunión de escuchar el intercambio del estudiante con el docente como así también realizar consultas e intervenciones. Proponer un espacio virtual de comunicación sincrónica con las características de las videollamadas, permitió asociar un rostro y una voz a los actores intervinientes por lo que consideramos que su uso fue beneficioso. Pero así también, presentó distintos inconvenientes. Puntualmente destacaremos dos. Por un lado, la complicación que suscitaba la conexión. En aquellos casos donde no se cuenta con una red Wifi para conectarse, el uso a través de los paquetes de datos provistos por empresas telefónicas tiene un costo significativo que considerar. Ya sea para los docentes o para los estudiantes, esta cuestión fue un impedimento para desarrollar algunas actividades con todos los actores. Por otro lado, el uso se hizo a través de su modalidad Basic o gratuita, con limitantes que fueron de peso al momento de la toma de decisiones. Por ejemplo, el límite por reunión es de 100 participantes; en un grupo de aproximadamente 200 estudiantes pensar una única reunión de todos fue inviable, por lo que su uso fue factible solo en grupos reducidos.

El empleo de la aplicación WhatsApp fue acertado, ya que entendemos que nos permitió generar un espacio menos abrumador para los estudiantes, al conformarse grupos reducidos, para que plantearan sus dudas. Además, nos brindó la posibilidad de dar los primeros pasos en el camino de la reflexión, el pensamiento crítico y la argumentación de los estudiantes respecto de sus trabajos y los de sus pares. Asimismo, es una aplicación que no ofrece barreras de conexión, por lo que se volvió un medio esencial para la comunicación de cada comisión.

Para concluir queremos enfatizar la importancia fundamental que tiene la planificación, en la cual se debe circunscribir toda propuesta de educación a distancia. Advertimos su carencia, ante esta situación extraordinaria, debido a que el desempeño de las clases demandó el uso simultáneo de diferentes herramientas y canales de comunicación, como así también de dispositivos y conectividad, en paralelo a la organización general, por parte del cuerpo docente. Sin embargo, se debe aclarar que esta planificación no debe ser rígida, siendo la autocrítica un elemento esencial para permitir revisar los procesos empleados y los resultados esperados.

Esta experiencia fue inigualable por las características que presentó; permitió conectar la teoría con una propuesta realizada en el marco 
de nuestras tareas inherentes a los cargos docentes, en un período corto, sin espacio para la transición y adaptación. Por último, afirmamos que son fundamentales para la implementación de cualquier propuesta educativa a distancia el compromiso, la confianza y el consenso del equipo docente y de los estudiantes, lo cual permitirá la creación del puente necesario para la construcción del conocimiento.

\section{BIBLIOGRAFIA}

Ahumada Torres, M. E. (2012). Innovando la docencia y la evaluación: las herramientas 2.0 al aula. Actual. Pedagog. N. ${ }^{\circ} 60$, julio-diciembre de 2012, pp. 15-28.

Andreoli, S. (2013). Herramientas de co-elaboración en educación. Escenarios educativos con tecnología. Primera edición. Dentro del Programa Virtual de Formación Docente del Centro de Innovación en Tecnología y Pedagogía (Citep) de la Secretaría de Asuntos Académicos del Rectorado de la Universidad de Buenos Aires. Argüelles, R. V. (2013). Las redes sociales y su aplicación en la educación. Revista Digital Universitaria, volumen 14, número 4. Coordinación de Acervos Digitales. Dirección General de Cómputo y de Tecnologías de Información y Comunicación - UNAM. http:// www.revista.unam.mx/vol. 14/num4/ art36/index.html

Facebook (2020). ¿Qué es un grupo de aprendizaje social en Facebook y cómo funciona? https://www.facebook. com/help/184985882229224

Gatica-Lara, Florina \& UribarrenBerrueta, Teresita del Niño Jesús (2013) ¿Cómo elaborar una rúbrica? Investigación en Educación Médica vol. 2, no. 5 Ciudad de México ene./

mar. 2013.

Grau, J. E. (Sin fecha). Módulo 1: Educación Virtual y funciones docentes. Curso: La función tutorial en la educación Virtual. Fundec.

Krause, F. (2018). El aula taller. El gigante olvidado en la didáctica arquitectónica. Reflexión Académica en Diseño y Comunicación, año XIX, agosto 2018, volumen 35, pp. 133-134 Padrón, C. J. (2013). Estrategias Didácticas basadas en Aplicaciones de Mensajería Instantánea WhatsApp exclusiva mente para Móviles (Mobile Learning) y el uso de la Herramienta para promover El Aprendizaje Colaborativo. Revista de Tecnología de Información y Comunicación en Educación, volumen 7, N. ${ }^{\circ} 2$, Julio-Diciembre 2013, pp. 123-134. Departamento de Tecnología de Servicios. Universidad Simón Bolívar, Camurí Grande, Estado Vargas, Venezuela.

Schwartzman, G. (2013). Materiales didácticos en educación en línea: por qué, para qué, cómo. En Brocca, D. I Jornadas Nacionales III Jornadas de la UNC: experiencias e investigación en educación a distancia y tecnología educativa. Universidad Nacional de Córdoba. Córdoba, 2013. http:// www.pent.org.ar/institucional/ publicaciones/dispositivostecnopedagogicos-linea-mediosinteractivos-para-aprender

Solano Fernández, Isabel María (2007). Diseño de presentaciones visuales para la docencia universitaria. En Prendes Espinosa, M. P., Herramientas telemáticas para la enseñanza universitaria en el marco del Espacio Europeo de Educación Superior. Grupo de Investigación de Tecnología Educativa, Universidad de Murcia. http://digitum.um.es/ xmlui/bitstream/10201/13413/1/ppt. 
